\title{
Femoral Neck Stress Fractures in Sport: A Current Concepts Review
}

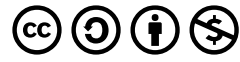

Authors

Greg A. Robertson ${ }^{1}$, Alexander M. Wood ${ }^{2}$

Affiliations

1 Edinburgh Orthopaedic Trauma Unit, Department of Orthopaedics, Royal Infirmary of Edinburgh, Edinburgh, United Kingdom of Great Britain and Northern Ireland

2 Bristol Royal Infirmary, Department of Orthopaedics, Bristol, United Kingdom of Great Britain and Northern Ireland

Key words

hip, pain, exercise, athlete, stress, fracture

received 15.10 .2016

revised $\quad 30.01 .2017$

accepted 02.02 .2017

Bibliography

DOI http://dx.doi.org/10.1055/s-0043-103946

Sports Medicine International Open 2017; 1: E58-E68

(c) Georg Thieme Verlag KG Stuttgart · New York

ISSN 2367-1890

\section{Correspondence}

Greg A Robertson, MBChB, BMedSci (Hons), MSc, MRCSEd

Edinburgh Orthopaedic Trauma Unit

Department of Orthopaedics,

Royal Infirmary of Edinburgh

51 Little France Crescent
EH16 4SA, Edinburgh

United Kingdom of Great Britain and Northern Ireland

Tel.: + 44/781/2898 697, Fax: + 44/131/2423541

greg_robertson@live.co.uk

\section{ABSTRACT}

Femoral neck stress fractures (FNSFs) account for $3 \%$ of all sport-related stress fractures. The commonest causative sports are marathon and long-distance running.

The main types of FNSF are compression-sided, tension-sided and displaced. The most common reported symptom is exercise-related groin pain. Radiographs form the first line of investigation, with MRI the second-line investigation.

The management of FNSFs is guided by the location and displacement of the fracture. Delay in diagnosis is common and increases the likelihood of fracture displacement. Sporting outcomes are considerably worse for displaced fractures. Education programmes and treatment protocols can reduce the rates of displaced FNSFs.

This article aims to provide a current concepts review on the topic of FNSFs in sport, assess the current evidence on the epidemiology and pathophysiology of these injuries, detail the current recommendations for their imaging and management, and review the recorded sporting outcomes for FNSFs in the existing literature.

From this study, we conclude that although FNSFs are a rare injury, they should be considered in all athletes presenting with exercise-related hip pain, because delay in diagnosis and subsequent fracture displacement can significantly impair future return to sport. However, when detected early, FNSFs show promising results in terms of return-to-sport rates and times.

\section{Introduction}

Femoral neck stress fractures (FNSFs) comprise around $3 \%$ of all stress fractures seen in the athlete [29]. Although rare, they have the potential to be one of the most serious injuries in sport, because left untreated, with subsequent fracture propagation and displacement, they can result in avascular necrosis (AVN) of the femoral head, necessitating a total hip replacement in a young athletic individual [37]. Around $50 \%$ of all athletes who suffer these injuries fail to return to previous sporting levels, with rates as high as $60 \%$ in those who suffer a displaced fracture [30].

The initial reports of these injuries were published by German military surgeons in 1905 [9] and 1936 [4]. Between then and 1990 , there had been a limited number of case series of these injuries, mainly from military personnel [12, 22, 24, 60]. However, since the early 1990 s, there have been increasing reports of this injury occurring in sporting individuals $[30,39,46,49]$, prompting the need for non-military medical staff to be more aware of FNSFs.

The importance of this condition is that if detected early and the injury is undisplaced, management and outcome have much higher success rates compared to FNSFs that remain undetected and displace [37, 39, 44, 45]. Early detection and management of undisplaced FNSFs have been associated with return rates as high as $100 \%$ to previous functional capacity, with rates as low as $0 \%$ for both the development of femoral head AVN and the need for delayed surgical intervention $[45,49]$. In contrast, displaced FNSFs have been associated with military discharge rates as high as $100 \%$ [44], with rates of post-treatment AVN and need for further intervention as high as $42 \%$ respectively [60]. Unsurprisingly, an increased awareness of such injuries among medical staff, along with educational programmes and established treatment protocols, has been shown to improve early detection of FNSFs, reducing rates of displaced fractures and improving outcomes of such injuries [44, 45, 52].

This article aims to provide a current concepts review on the topic of FNSFs in sport, assess the current evidence on the epidemiology and pathophysiology of these injuries, detail the current recommendations for their imaging and management, and review the recorded sporting outcomes for FNSFs in the existing literature. 


\section{Methodology and Objectives}

\section{Methodology}

The search methodology for the review comprised a systematic literature search in October 2016 of the following databases: Medline (PubMED), Cochrane Collaboration Database, EMBASE, SPORTDiscus, CINAHAL, Google Scholar, Physiotherapy Evidence Database (PEDro), Scopus and Web of Science. The key words used were 'femoral', 'neck', 'stress', 'fracture', 'athlete', 'sports' to locate all articles published in the English language in peer-reviewed journals that provided information on the epidemiology, pathophysiology, assessment, management and return to sport following treatment for FNSFs. There was no limit regarding the year of publication. All article categories including case reports, expert opinions, literature reviews, instructional courses, biomechanical reports, and technical notes were reviewed to determine if they provided relevant information

\section{Objectives}

The main objectives of the review article were to:

- provide concise information on the epidemiology and risk factors for FNSFs;

- detail the current concepts on the pathophysiology of these injuries;

- define the standard clinical presentation and examination findings for FNSFs;

- determine the evidence-based recommendations for radiological imaging of these injuries;

- determine the evidence-based recommendations for management of these injuries;

- review the evidence regarding return to sport for FNSFs;

- establish the benefit of injury prevention programmes for this injury type.

\section{Epidemiology and Risk Factors}

\section{Epidemiology}

The only study to provide an accurate incidence of sport-related FNSFs is that by Hulko \& Ovara [29], who noted 9 FNSFs from a cohort of 368 stress fractures, recorded over a 14-year study period. The incidence of FNSFs will, however, vary based on the intensity and level of sport played, as well as the nature of the sport [53].

As a cohort, FNSFs comprise around $3 \%$ of all stress fractures in athletes [29]. Regarding stress fractures of the femur, FNSFs represent the highest proportion of these, comprising $50 \%$ of such injuries [40].

The reported mean age within FNSF cohorts varies from 16 to 56 years. Higher incidences of FNSFs are seen among female athletes [29]. Hulko \& Ovara [29] noted that FNSFs comprised $4.1 \%$ of all stress fractures in their female athletes but only $1.8 \%$ of all stress fractures in their male athletes. Within athletic cohorts, the most commonly reported causative sports are marathon running, long-distance running, basketball, gymnastics and ballet dancing $[8,30,37,39]$.

\section{Risk factors}

Recent data from a case-control study of 47 military trainees who sustained FNSFs showed that the main risk factors for this injury were female gender and poor baseline physical fitness [35]. Body mass index was not observed as a risk factor [35].

Key factors postulated for the increased risk seen in the female gender are the effects of abnormal physiology secondary to the components of the female athlete triad, namely disordered eating, amenorrhoea and decreased bone mineral density [26, 27, 35, 43].

Previous data by Pouilles et al. [47] also confirmed that decreased femoral bone mineral density (BMD) is associated with an increased risk of sustaining an FNSF. Pouilles et al. [47] found that the femoral BMD of military recruits who sustained FNSFs was around $10 \%$ less than a matched control cohort.

Further factors found to pre-dispose individuals to develop FNSFs include a sudden increase in training intensity, coxa vara, coxa profunda and acetabular retroversion, as seen in pincer-type femoral acetabular impingement (FAI) $[14,25,39]$. However, an established link between FNSF and FAI has yet to be confirmed $[25,34,59]$.

\section{Classification, Pathophysiology and Biomechanics}

\section{Classification ( $>$ Fig. 1)}

Since the 1960s, there have been multiple attempts to classify FNSFs $[12,17,22]$.

The mostly commonly used classification at present is that of Fullerton \& Snowdy [24], who categorized FNSFs into 3 groups, using both plain radiographs and bone scans. Type I fractures occurred on the tension-side of the femoral neck, type II fractures on the compression-side and type III fractures were displaced [24].

This classification was further developed by Shin \& Gillingham [53]. Based on MRI findings of FNSFs, they subdivided compression injuries into those without a fracture line, those with a fracture line less than $50 \%$ of the femoral neck width, and those with a fracture line greater than or equal to $50 \%$ of femoral neck width [53].

Further additions to the Fullerton \& Snowdy [24] classification include those by Provencher et al. [48], who reported a fourth category, namely an atypical superiorly based incomplete tension-type fracture, which is routinely absent on plain radiographs though present on MRI [48].

More recently, Arendt \& Griffth [2] presented a MRI-based classification system that has been validated to predict the outcome of FNSF [2,49]. Divided into 4 grades, Grade 1 shows signal change on STIR sequencing exclusively; Grade 2 shows change on STIR and T2; Grade 3 shows change on STIR, T1, and T2 but with no fracture line present; and Grade 4 shows change on STIR, T1, and T2 but with a fracture line present [2].

\section{Pathophysiology and biomechanics}

FNSFs develop in response to repetitive sub-maximal mechanical loads applied across the femoral neck, when the absorption of bone exceeds metabolic repair during the remodelling process $[8,19,31,53]$. The vast majority of FNSFs in athletes are fatigue 


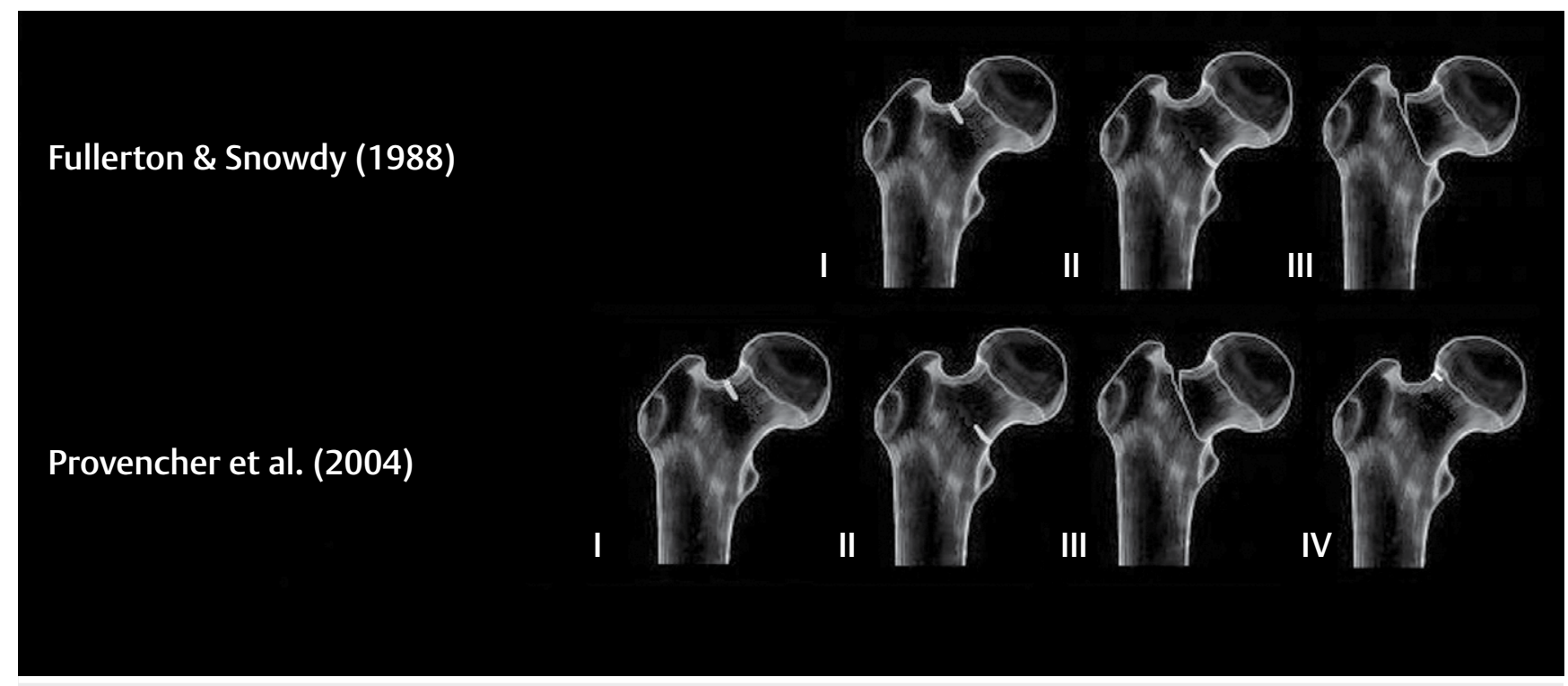

Fig. 1 The classification systems for femoral neck stress fractures.

fractures induced by repetitive loading of normal bone with abnormal forces $[8,19,31,53]$. However, FNSFs that develop along with female athlete triad are, in effect, partial insufficiency fractures, because they develop in abnormal bone $[8,19,31,53]$.

Forces up to 3 to 5 times body weight can be transferred along the femoral neck during activities such as jogging [19, 53]. The vast majority of these are compressive-type forces, which occur at the inferior aspect of the neck $[19,53]$. Significant tensile forces can develop at the superior aspect of the femoral neck due to bending forces across the neck: however, these are normally counterbalanced through the stabilising forces of gluteus medius and minimus $[19,53]$.

Compression FNSFs develop from the compression forces at the inferior aspect of the femoral neck. When the forces applied exceed the elastic properties of bone and outpace the healing response of bone, microfractures develop and propagate at 45 degrees to the application of forces $[19,53]$. This creates an oblique fracture line across the femoral neck, which can remain stable until it exceeds around $50 \%$ of the femoral neck width $[19,53]$. The fracture line created with a compression fracture is more oblique than that of a tension fracture, and is thus more stable and less likely to displace [50].

Tension FNSFs arise from the tension forces at the superior aspect of the femoral neck $[19,53]$. While normally counterbalanced by the forces of the gluteus medius and minimus, when these muscles fatigue, high tension forces develop across the superior femoral neck on load bearing $[19,53]$. This results in microfracture formation and propagation with subsequent fracturing of the superior aspect of the femoral neck $[19,53]$. Such a fracture line propagates at 90 degrees to the broken cortex, creating a transverse fracture, which is more unstable than that of the compression fracture, with a higher likelihood of displacement $[19,53]$. Note that altered hip geometry such as coxa vara can decrease the efficiency of the gluteal muscles, promoting early fatigue of these muscles and development of tension-sided FNSFs [14].

\section{Clinical Presentation, Examination and Investigations}

\section{Clinical presentation}

The common presenting complaint with FNSFs is that of a gradual onset hip or groin pain that is poorly localized, aggravated by activity and weight-bearing, and ceases with rest $[19,39,53]$. The pain is most often sited at the anterior groin region (reported in $87 \%$ of patients in one study) [24,39]; however this can be located at the thigh or gluteal region and can radiate to the knee $[19,39,51,53]$. Patients often note a recent increase in intensity or duration of exercise, such as preparation for a marathon or a sports event [19, 39, 53].

Typically, the pain is initially noted late in activity and then increases in intensity with prolonged participation in exercise, often limiting or prohibiting further activity $[19,24,39,53]$. This is regularly associated with an antalgic gait $[19,24,39,53]$. Eventually the pain is noted at rest and at night $[19,24,53]$.

These symptoms can be followed by an episode of the hip giving way or 'cracking' or 'popping' during exercise as the fracture completes and displaces [26, 27]. Occasionally, little pain is experienced until the patient suffers a complete fracture $[19,53]$.

As soon as the diagnosis of FNSF is suspected, the patient should cease weight-bearing on the affected hip and a screening radiograph should be performed urgently $[8,19,53]$.

\section{Examination}

Physical examination can often be non-specific, though the most consistent findings are pain at the extremes of hip range of motion (present in $79 \%$ of FNSF patients in one study) [24,39], especially with internal rotation $[19,39,53]$. Tenderness on palpation over the anterior aspect of the hip and the inguinal area is also a common finding (present in $62 \%$ of FNSF patients in one study) $[19,24,39,53]$. The pain can be aggravated if the patient performs a straight-leg raise or if the examiner logrolls the thigh $[19,53]$. 

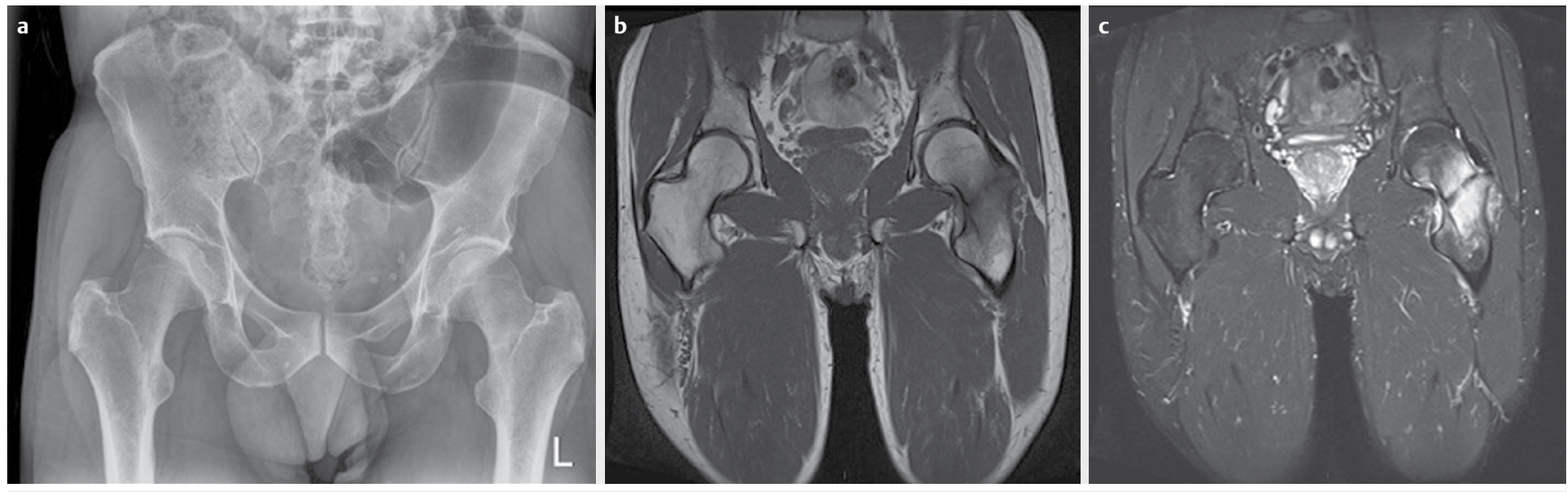

Fig. 2 A complete compression femoral neck stress fracture: a radiograph; b t1 sequence mri; $\mathbf{c}$ stir sequence MRI.

Heel strike testing is of limited value in diagnosing FNSF (present in $6 \%$ of FNSF patients in one study) $[19,24,53]$.

A complete examination should include assessment of the lower lumbar and sacral spine, the lower extremities, and the contralateral hip so that alternative causes for the symptoms are not missed $[1,19,42,53]$.

\section{Investigations}

\section{Radiographs}

Plain radiographs form the first-line imaging investigation for FNSFs [56]. An anteroposterior view of the pelvis (including the proximal third of the femur) and a direct lateral view of the proximal femora should be acquired $[10,19,53,56]$ in all athletes who present with exercise-related hip or groin pain that is exacerbated by weight-bearing.

When present, the key radiographic changes are periosteal and endosteal callous formation, a sclerotic linear region traversing the primary trabeculae of the femoral neck and a radiolucent fracture line ( $\triangleright$ Fig. 2) [10, 56]. Such changes, however, are often subtle; assessment of the radiographs with magnification is regularly required, along with comparison against the adjacent side.

However, as many as 2 thirds of FNSF patients show no changes on radiographs on presentation $[10,53,56]$. Typically, around 6 to 8 weeks is required before stress-related changes are visible on radiographs; however, around half of all FNSF patients will never have radiographic evidence of osseous change $[10,53,56]$. With negative radiographs, and history and examination findings in keeping with a suspected femoral neck stress fracture, further imaging is required $[10,56]$.

\section{Magnetic resonance imaging}

Magnetic resonance imaging (MRI) has now become the gold-standard second-line imaging investigation for FNSFs $[10,53,54,56]$. A scan should be ordered for all athletes with a suspected FNSF and whose X-rays are negative $[10,53,54,56]$. An MRI has been shown to have $100 \%$ sensitivity, specificity and accuracy when investigating for FNSFs, offering an unrivalled ability to specify differential diagnoses if present [54].

The standard features of FNSFs found on MRI scanning include: a diffuse, ill-defined, rounded hypo-intense area on T1-weighted images with an equivalent hyper-intense signal on both fat-sup-
- Table 1 The management of femoral neck stress fractures by fracture type.

\begin{tabular}{|l|l|l|}
\hline Fracture Type & $\begin{array}{l}\text { Incomplete } \\
\text { (<50\% Femoral } \\
\text { Neck Width) }\end{array}$ & $\begin{array}{l}\text { Complete } \\
\text { (>50\% Femoral } \\
\text { Neck Width) }\end{array}$ \\
\hline Compression & $\begin{array}{l}\text { Conservative } \\
- \text { unless significant } \\
\text { pain or unable to } \\
\text { straight-leg raise }\end{array}$ & $\begin{array}{l}\text { Surgical Fixation } \\
\text { (Cannulated Hip } \\
\text { Screws or Dynamic } \\
\text { Hip Screw) }\end{array}$ \\
\hline Tension & Surgical Fixation & Surgical Fixation \\
& (Dynamic Hip Screw) & (Dynamic Hip Screw) \\
\hline Displaced & & $\begin{array}{l}\text { Immediate } \\
\text { Reduction and } \\
\end{array}$ \\
& & Surgical Fixation \\
& & $\begin{array}{l}\text { (Dynamic Hip } \\
\text { Screw } \pm \text { Derotation } \\
\text { Screw) }\end{array}$ \\
\hline Atypical Tension & Conservative & Surgical fixation \\
& & (Dynamic Hip Screw) \\
\hline
\end{tabular}

The preferred surgical techniques for each fracture type have been provided in parentheses in the relevant boxes

pressed T2-weighted images and short-tau inversion-recovery (STIR) sequencing ( $>$ Fig. 2) $[10,53,56]$. With worsening severity of the stress injury, these signals are found to span an increasing width of the femoral neck $[10,53,56]$. When present, a fracture line is seen as a linear area of hypo-intense signal, extending at right angles from the affected cortex, and visible on all sequences of the MR scan $[10,53,56]$. These findings on MRI images are usually present several weeks before the appearance of radiographic changes $[10,53,56]$.

Specific benefits of MRI scanning for FNSF investigation include the fact that it is minimally invasive, involves no exposure to ionizing radiation, is cost-effective, and can provide accurate diagnostic information about the surrounding anatomy $[10,32,53,56]$.

\section{Bone scan}

Isotopic bone scanning has now been largely superseded by MRI scanning for the assessment of FNSFs $[10,19,53,56]$. Previously, it was the gold-standard second-line investigation for evaluating FNSFs, with sensitivity rates ranging from $93 \%$ to $100 \%$ and spec- 


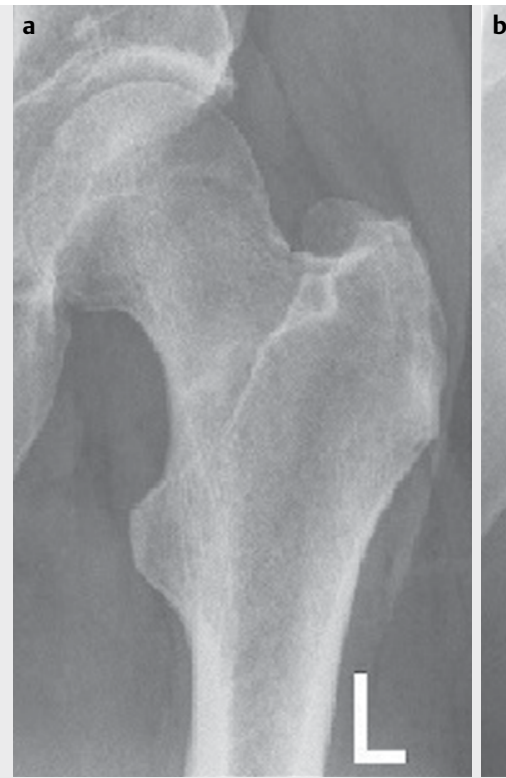

b
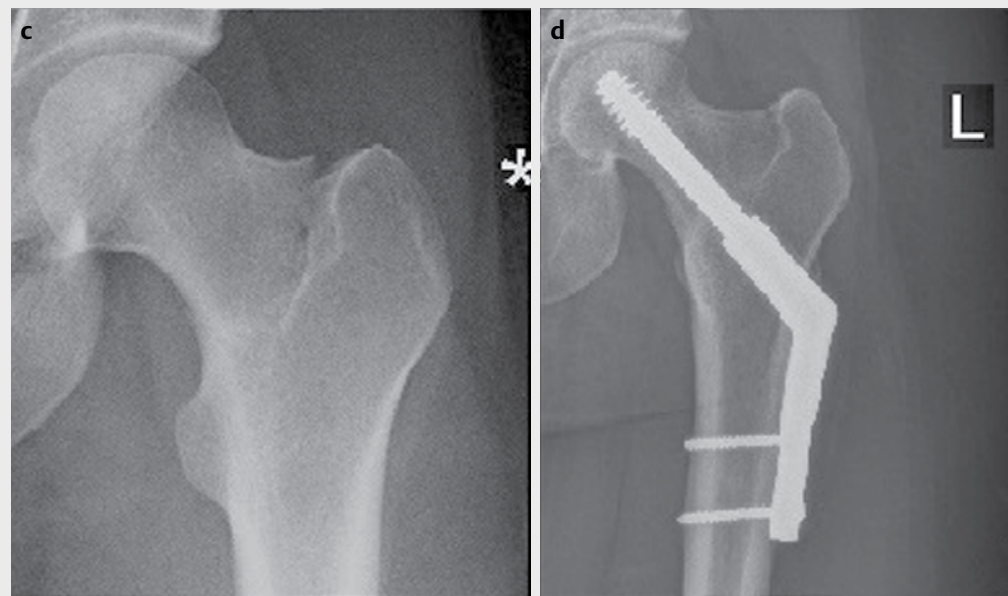

e

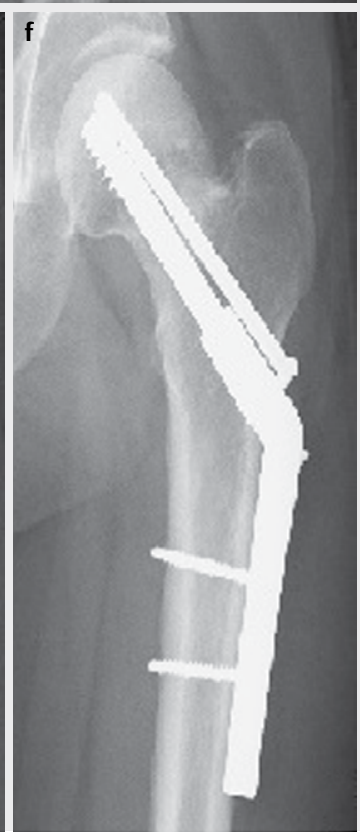

- Fig. 3 A complete compression fracture treated with cannulated hip screws: a pre-operative; b post-operative. a complete tension fracture treated with a dynamic hip screw: $\mathbf{c}$ pre-operative; $\mathbf{d}$ post-operative. a displaced fracture treated with a dynamic hip screw and de-rotation screw: e pre-operative; $\mathbf{f}$ post-operative. 
ificity rates ranging from $76 \%$ to $95 \%$ in assessing stress fractures $[10,19,53,56]$. However, with false positive rates as high as $32 \%$ in assessing patients with suspected FNSFs, as well as a requirement for radiation exposure, bone scans are inferior to MRI for FNSF imaging [54].

\section{Blood profile}

In addition to imaging investigations, all patients should undergo routine comprehensive blood testing including a full blood count, erythrocyte sedimentation rate, C-reactive protein levels, renal and liver profile, serum calcium and albumin, with an additional hormone profile for females $[19,26,43,53]$.

\section{General assessment}

In addition to imaging and blood investigations, a comprehensive assessment of each individual should be performed, recording dietary habits, training profiles, gait biomechanics, baseline fitness levels, suitability of training equipment, and use of associated medications, in order to diagnose and adjust pre-disposing factors for this condition [8].

\section{Management and Complications}

\section{Management}

The management of FNSFs is decided upon by the location, extent (complete or $>50 \%$ femoral neck width; incomplete or $<50 \%$ femoral neck width) and displacement of the fracture ( $\triangleright$ Table 1) [24, 52, 53].

FNSFs which can be managed conservatively include incomplete compression and incomplete atypical tension fractures ( $\triangleright$ Fig. 3) $[24,52,53]$. Those which require surgery include complete compression fractures, complete tension fractures and displaced fractures ( Fig. 3) [24, 52, 53]. There remains debate regarding incomplete tension fractures, with some advocating conservative treatment $[3,24,45]$, whereas the majority advocate surgical management to avoid potential displacement and the significant complications that can arise [52,53].

When a diagnosis of a completed FNSF is made, initial bed rest in mandatory prior to surgical intervention, because even with non- weight-bearing, the ipsilateral muscle activation required to stabilise the pelvis can result in fracture displacement $[3,24,45]$.

\section{Surgical management}

Timing of surgery

It is becoming increasing clear that delayed surgery for displaced FNSFs results in higher rates of post-operative AVN and failure of fixation [23, 30, 37]. In a series of 42 displaced FNSFs, Lee et al. [37] noted that in FNSFs which developed $\operatorname{AVN}(n=10)$, the mean delay until surgery was 5.9 days, whereas in those that did not develop $\operatorname{AVN}(n=32)$, the mean delay was 1.9 days. Johansson et al. [30] noted an AVN rate of $30 \%$ in a cohort of 10 displaced FNSF in athletes who had delayed treatment by a mean of 14 weeks. In contrast, Evans et al. [23] noted a $0 \%$ AVN rate in a cohort of 6 displaced FNSFs operated on within $12 \mathrm{~h}$.

\section{Choice of implant}

There is limited evidence to guide the choice of implant in FNSFs [37]. The study by Lee et al. [37] noted that in 22 cases of displaced FNSFs, those treated by closed reduction and multiple cannulated screws (MCS) had an AVN rate and subsequent revision rate of $18 \%$ (4/22); yet those treated by closed reduction and dynamic hip screw (DHS) also had an AVN rate and subsequent revision rate of $18 \%(3 / 17)$ [37].

Compression FNSFs display a more oblique fracture pattern which, biomechanically, is more stable, and thus can be safely fixed with MCS $[24,50]$. Tension-type FNSFs, however, are more vertical in nature and prove to be more unstable following fixation; a DHS is recommended for these fracture types because it provides more robust fixation $[21,24,50]$. With displaced FNSFs, a DHS with a de-rotation screw is recommended, because it provides the stablest construct and reduces the risk of rotating the femoral head during screw insertion, thus limiting damage to the femoral head blood supply [21, 24, 37, 50].

\section{Reduction alignment}

The evidence from Lee et al. [37] has shown that there is a high failure rate with displaced FNSFs that are fixed in varus alignment, compared to those that are fixed in valgus or neutral alignment. In their series, $71 \%$ (5/7) of the cases with post-operative varus align-

- Table 2 Study data and systematic review data on return to sport following femoral neck stress fractures.

\begin{tabular}{|c|c|c|c|c|c|}
\hline Study & $\mathbf{n}$ & $\begin{array}{l}\text { Return-to-Sport } \\
\text { Rates }\end{array}$ & Sub-Cohorts & $\begin{array}{l}\text { Return-to- } \\
\text { Sport Times }\end{array}$ & Sub-Cohorts \\
\hline \multirow{3}{*}{$\begin{array}{l}\text { Johansson et al. } \\
(1990)\end{array}$} & 23 & $12 / 23(52 \%)$ & Blickenstaff \& Morris Type 1: 6/9 (69\%) & - & - \\
\hline & & & Blickenstaff \& Morris Type 2: 2/4 (50\%) & & \\
\hline & & & $\begin{array}{l}\text { Blickenstaff \& Morris Type 3: 4/10 } \\
(40 \%)\end{array}$ & & \\
\hline \multirow[t]{4}{*}{ Ramey et al. (2016) } & 27 & $27 / 27(100 \%)$ & Arendt Grade 1: 5/5 (100\%) & 14.1 weeks & Arendt Grade 1: 7.4 weeks \\
\hline & & & Arendt Grade 2: 5/5 (100\%) & & Arendt Grade 2: 13.8 weeks \\
\hline & & & Arendt Grade 3: 8/8 (100\%) & & Arendt Grade 3: 14.7 weeks \\
\hline & & & Arendt Grade 4: 9/9 (100\%) & & Arendt Grade 4: 17.5 weeks \\
\hline \multirow{4}{*}{$\begin{array}{l}\text { Neubauer et al. } \\
\text { (2016) }\end{array}$} & 48 & $28 / 42(67 \%)$ & Low-Performance Runner 23/32 (72\%) & - & - \\
\hline & & & High-Performance Runner 5/16 (31\%) & & \\
\hline & & & Displaced Fractures 6/18 (33\%) & & \\
\hline & & & Non-Displaced Fractures 22/30 (73\%) & & \\
\hline
\end{tabular}




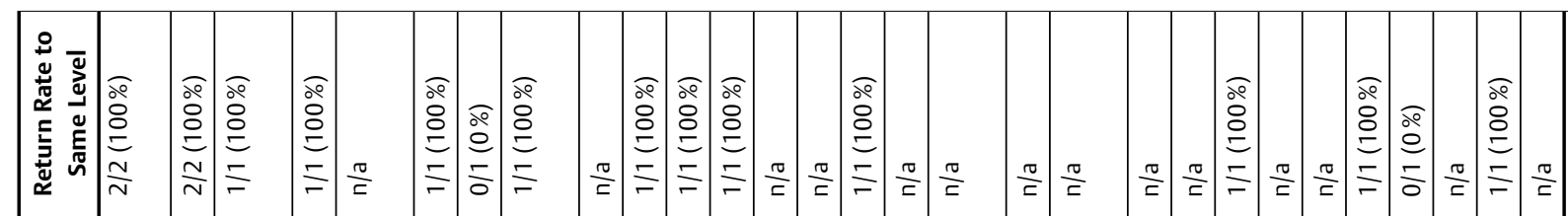

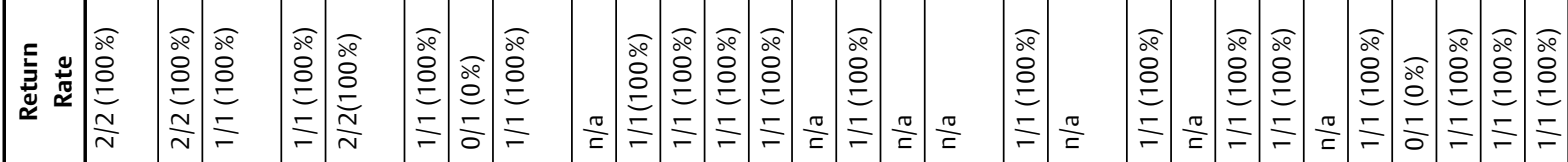

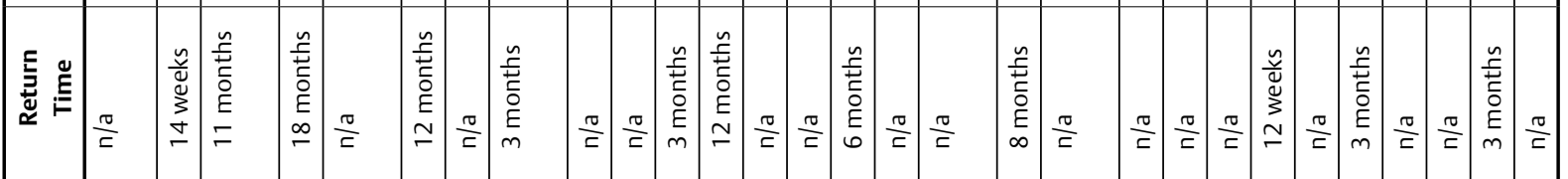

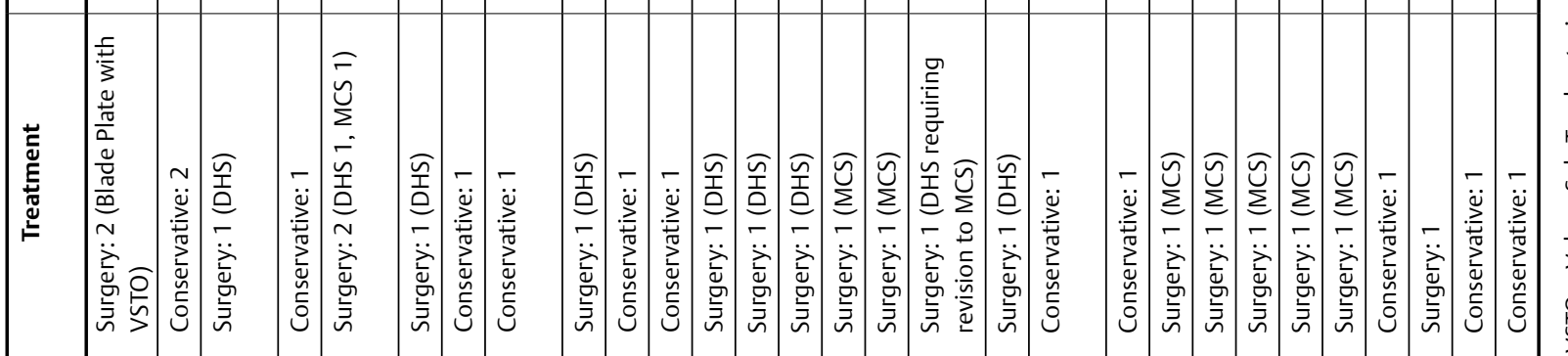

m.

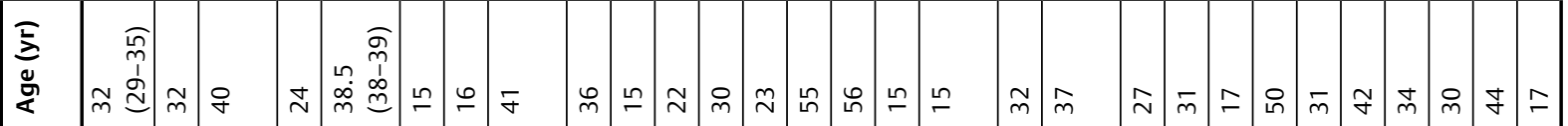

旁

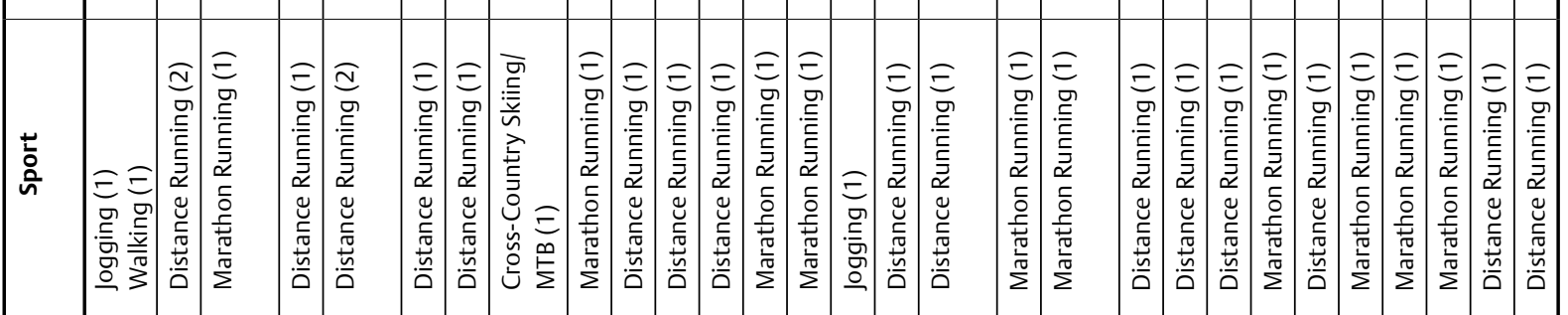

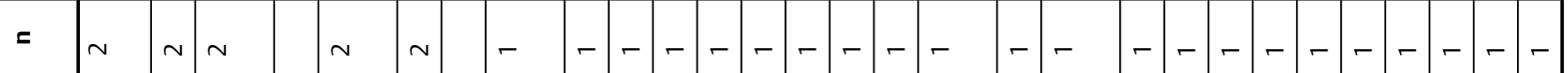

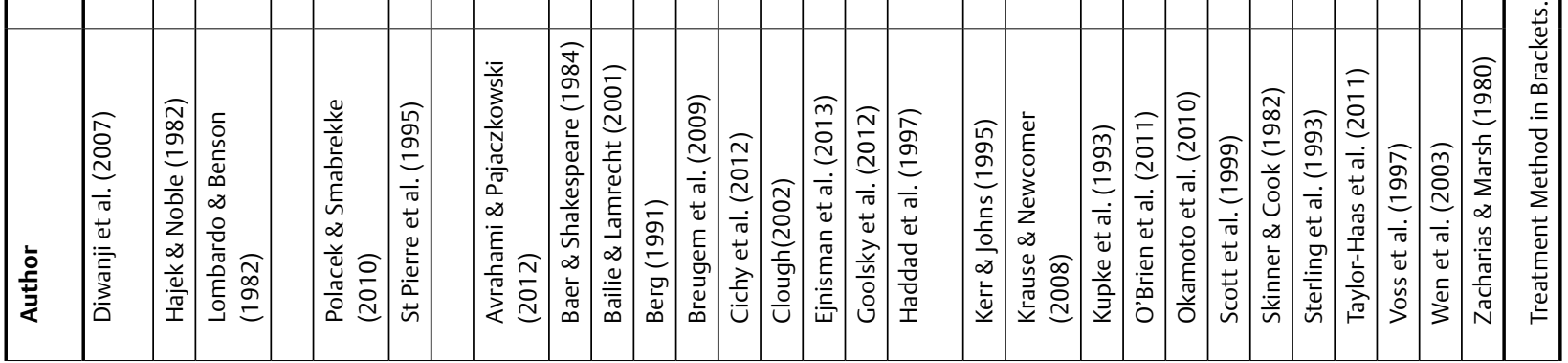


ment developed AVN compared to $14 \%$ (5/35) of the cases with post-operative valgus or neutral alignment [37].

\section{Rehabilitation}

Post-operatively, the patient should remain non- to toe-touch weight-bearing with crutches for 6 weeks, followed by partial weight-bearing with crutches for a further 6 weeks [20, 24, 26, 51]. After this, weight-bearing is permitted as tolerated [20, 24, 26, 51]

Upper limb conditioning can commence immediately post-operatively [15]. Hydrotherapy can then begin 2 weeks post-surgery, wearing an inflatable jacket for support [51]. Lower-limb athletic activity should be commenced only when there is clear evidence of fracture union, both radiologically and clinically [31]. Activity is normally commenced in a graduated manner, around 12 weeks post-surgery, with input from the physiotherapists, specifically focussing on strengthening and range-of-motion exercises around the hip [20, 24, 49, 51]. Patient should begin with a gentle running programme, which should be increased in intensity over 6 to 8 weeks, ensuring the patient remains pain-free throughout $[20,24,49,51]$. Return to full sport can normally be achieved between 3 and 6 months post-surgery, though this can require up to a year if not longer $[20,24,31,46]$.

In all cases, dedicated regular follow-up is required with sequential radiographs to assess that the fracture unites and that the fixation does not lose reduction and displace $[20,24,31,46]$. If this is occurs, non-weight-bearing should be resumed immediately and revision surgery considered if required $[24,31,46]$. Clinical and radiographic follow-up should be maintained for a minimum of 2 years to ensure delayed post-treatment AVN does not ensue [24,31,46].

\section{Conservative management}

\section{Rehabilitation}

If conservative management is chosen, then the patient should be limited weight-bearing with crutches until they are completely free of pain $[5,24,45,49]$. This normally takes between 6 to 8 weeks but can be up to 14 weeks [5, 24, 45, 49]. During this time, weight-bearing through the injured side can be gradually increased from non-weight-bearing to toe-touch weight bearing to partial weight-bearing, as pain allows [5, 24, 45, 49].

Rehabilitation should be similar to that described for post-operative care [24, 31, 45, 49]. Lower-limb athletic activity should be commenced only when there is clear evidence of fracture union, both radiologically and clinically $[31,49]$. The patient should be pain-free with full activity before returning to full level sport $[24,31,45,49]$. This can normally be resumed around 12 weeks post-injury, but can take up to 28 weeks [24, 31, 45, 49].

In all cases, dedicated regular follow-up with serial radiographs is required to assess that FNSFs do not propagate and displace $[24,31,45,49]$. As a guide, radiographs should be performed weekly for the first 4 weeks, every 2 weeks for the next 4 weeks and then every 4 weeks for the next 8 weeks $[24,31,45,49]$. If fracture propagation or displacement occurs, non-weight-bearing should be resumed immediately and surgical fixation performed [24, 31, 45, 49].

Note if patients treated conservatively for incomplete compression fractures complain of significant pain or are unable to straightleg raise, then they should be considered for surgical fixation [52].

\section{Complications}

The incidence of complications following FNSFs largely depends on the nature of the fracture, particularly whether the fracture is displaced or undisplaced $[19,53]$.

Multiple series of undisplaced conservatively managed FNSFs with prolonged follow-up reported no significant complications beyond refracture [24, 30, 45, 49]. As an exception, however, Blickenstaff \& Morris [12] reported that half of their undisplaced tension fractures healed in varus malunion and advised early surgical intervention for this injury type.

Displaced FNSFs, however, with their required surgical management, often develop significant complications [19,53]. These commonly include AVN (24-42\%) [30, 37, 44, 60], non-union (16-44\%) $[12,44,60]$, delayed union $(8-50 \%)[23,37,44,60]$, malunion $(5-33 \%)[12,44]$, failure of fixation (14\%) [37], revisional surgery (21-50\%) [30, 37, 44, 60] and long-term OA (68\%) [44]. Such complications can, however, be limited by rapid intervention; surgery within $12 \mathrm{~h}$ post-injury has been shown to offer an AVN rate of $0 \%$ and a revisonal surgery rate of $0 \%$ [23].

\section{Return to Sport and Injury Prevention}

\section{Return to sport}

The return-to-sport data in the current literature for athletes with FNSFs is limited, with only 2 studies and one systematic review providing comprehensive information on return to sport for these injuries ( $\triangleright$ Table 2 ) $[30,49]$. The remaining literature is restricted to case reports and case series ( $\triangleright$ Table 3 ) $[5-7,11,13,15,16,18$, 20, 26-28, 32, 33, 36, 38, 41, 43, 46, 51, 55, 57-59, 61-63].

Until recently, the only comprehensive study to assess the sporting outcome in athletes with FNSFs was that by Johansson et al. [30]. They reported a series of 7 elite and 16 recreational Swedish athletes with FNSFs sustained from a variety of sports [30]. 16 underwent surgical fixation with 7 treated conservatively [30].

From the whole cohort, 12 (52\%) returned to same level of sporting activity post-treatment; however all elite athletes had to end their career secondary to their injury [30]. Those with displaced fractures had significantly worse return rates to sport (40\%) than those with non-displaced fractures (62\%).

More recently, Ramey et al. [49] published a study assessing the 'return to running time' for 27 conservatively managed compression FNSFs in 24 runners ( 3 recurrent fractures in a single patient). Grading the FNSFs by the Arendt scale [2], the mean time to return to running was 14.1 weeks; increased severity per the Arendt scale was associated with an increased return to running time [49].

In 2016, Neubauer et al. [39] published a systematic review recording all reported cases of running athletes who sustained an FNSF. From a cohort of 48 athletes, 28 were noted to return to running [39]. Fracture displacement $(p=0.014)$ and high performance running status $(p=0.012)$ were found to negatively influence the return to running ( $\triangleright$ Table 2 ) [39].

From the cohort of case reports, a total of 32 athletes were recorded (17 female:15 male) ( Table 3 ) $[5-7,11,13,15,16,18$, $20,26-28,32,33,36,38,41,43,46,51,55,57-59,61-63]$. The causative sports were long-distance running in 18 cases, marathon running in 10 , jogging in 2 , walking in one and skiing in one [5- 
Table 4 Summary table.

\begin{tabular}{|c|c|}
\hline & Key Findings \\
\hline Epidemiology & $\begin{array}{l}\text { - FNSFs comprise } 3 \% \text { of all sport-related } \\
\text { stress fractures. } \\
\text { - Long-distance running and marathon } \\
\text { running are the main causative sports. } \\
\text { - Female gender and low baseline physical } \\
\text { fitness are the main risk factors. }\end{array}$ \\
\hline Pathophysiology & $\begin{array}{l}\text { - Compression FNSFs develop as a result of } \\
\text { fatigue loading of the femoral neck. } \\
\text { - Tensions FNSFs develop in conjunction with } \\
\text { weakening of the hip abductor muscles. }\end{array}$ \\
\hline Biomechanics & $\begin{array}{l}\text { - Compression FNSFs form an oblique } \\
\text { fracture line with a stable fracture pattern. } \\
\text { - Tension FNSFs form a vertical fracture line } \\
\text { with an unstable fracture pattern. }\end{array}$ \\
\hline Presentation & $\begin{array}{l}\text { - The most common reported symptom is } \\
\text { exercise-related anterior groin pain. }\end{array}$ \\
\hline Examination & $\begin{array}{l}\text { - The most common exam finding is pain at } \\
\text { the extremes of hip range of motion }\end{array}$ \\
\hline Investigation & $\begin{array}{l}\text { - Plain radiographs form the first-line } \\
\text { imaging investigation for FNSFs. } \\
\text { - MRI scan is now the gold-standard } \\
\text { second-line imaging investigation for } \\
\text { FNSFs. }\end{array}$ \\
\hline Management & $\begin{array}{l}\text { - Incomplete ( }<50 \% \text { FNW) compression } \\
\text { FNSFs are managed conservatively. } \\
\text { - Complete compression and incomplete } \\
\text { tension FNSFs are managed surgically. } \\
\text { - Displaced FNSFs require urgent reduction } \\
\text { and surgical fixation. } \\
\text { - The choice of surgical fixation is guided by } \\
\text { the fracture pattern. }\end{array}$ \\
\hline Sport Outcome & $\begin{array}{l}\text { - Incomplete compression FNSFs demon- } \\
\text { strate good sporting outcomes, with } \\
\text { reported return rates of } 100 \% \text { and return } \\
\text { times of } 14 \text { weeks. } \\
\text { - Displaced FNSFs demonstrate less } \\
\text { favourable sporting outcomes, with } \\
\text { reported return rates ranging } 33-100 \% \\
\text { and return times ranging from } 3 \text { to } 12 \\
\text { months. } \\
\text { - Fracture displacement and high-perfor- } \\
\text { mance running status have been found to } \\
\text { negatively influence return to sport. }\end{array}$ \\
\hline Injury Prevention & $\begin{array}{l}\text { - Education programmes and treatment } \\
\text { algorithms can reduce rates of displaced } \\
\text { FNSFs. } \\
\text { - Regulated exercise programmes are } \\
\text { recommended for endurance runners. }\end{array}$ \\
\hline
\end{tabular}

$7,11,13,15,16,18,20,26-28,32,33,36,38,41,43,46,51,55$, 57-59,61-63]. There were 12 conservatively managed compression fractures, 15 surgically managed displaced fractures and 5 surgically managed undisplaced fractures $[5-7,11,13,15,16,18,20,26-$ $28,32,33,36,38,41,43,46,51,55,57-59,61-63]$. For the conservatively managed compression FNSFs, the combined return rate was $9 / 11$; the return times ranged from 3 to 18 months $[5,7,11$, $28,33,36,38,57,59,62,63]$. For the surgically managed displaced FNSFs, the combined return rate was $11 / 11$; the return times ranged from 3 to 12 months $[15,16,18,20,26,27,32,38,43,46$, $51,55,57]$. For the surgically managed nondisplaced fractures, the combined return rate was $3 / 3$; the return times ranged from 3 months to 12 months $[6,13,41,58,61]$.

\section{Injury prevention}

Treatment protocols introduced by the Finnish and US military, which advocated prompt imaging of all symptomatic servicemen, along with educational programmes for the healthcare providers, have been found to reduce rates of displaced FNSFs by over $50 \%$ $[35,44,45,53]$. Similar guidance should be provided for healthcare professionals managing athletic populations $[35,44,45,53]$.

Regarding exercise training modifications to avoid FNSFs, current recommendations advise that athletes should limit training volume increases to $10 \%$, and that, for beginners, total training volume should not exceed $160 \mathrm{~km}$ over a 12 week period [39].

\section{Conclusion ( $\triangleright$ Table 4)}

From this review article, it has been established that FNSFs comprise $3 \%$ of all sport-related stress fractures. The main causative sports are long-distance and marathon running. Female gender and poor baseline physical fitness are the key risk factors for these injuries. Compression FNSFs develop secondary to exercise-related fatigue loading of the femoral neck; tensions FNSFs develop both through this and through fatigue of the hip abductor muscles. The commonest presenting symptom is exercise-related anterior groin pain; the commonest exam finding is pain at the extremes of hip range of motion. Radiographs form the first line of imaging: MRI scans are now the gold-standard second-line imaging investigation. The management of FNSFs remains guided by the location and displacement of the fracture: conservative management is reserved for incomplete compression FNSFs; surgical management is required for complete compression FNSFs and tension FNSFs. Displaced FNSFs should be treated by urgent reduction and surgical fixation. Sporting outcomes are favourable for incomplete compression fractures, with return rates as high as $100 \%$ : however they are considerably worse for displaced fractures, with return rates as low as $33 \%$. Education programmes and treatment algorithms can reduce the incidence of displaced FNSFs in the athlete.

\section{Conflict of Interest}

The authors declare that they have no conflict of interest.

\section{References}

[1] Adkins SB $3^{\text {rd }}$, Figler RA. Hip pain in athletes. Am Fam Physician 2000; 61: 2109-2118

[2] Arendt EA, Griffiths HJ. The use of MR imaging in the assessment and clinical management of stress reactions of bone in high-performance athletes. Clin Sports Med 1997; 16: 291-306

[3] Aro H, Dahlstrom S. Conservative management of distraction-type stress fractures of the femoral neck. J Bone Joint Surg Br 1986; 68: 65-67 
[4] Asal D. Uberlastungsschaden am Knochensystem bei Soldaten. Arch für Klinische Chirurgie 1936; 186: 511-522

[5] Avrahami D, Pajaczkowski JA. Femoral neck stress fracture in a female athlete: a case report. J Chiropr Med 2012; 11: 273-279

[6] Baer S, Shakespeare D. Stress fracture of the femoral neck in a marathon runner. Br J Sports Med 1984; 18: 42-43

[7] Bailie DS, Lamprecht DE. Bilateral femoral neck stress fractures in an adolescent male runner. A case report. Am J Sports Med 2001; 29: 811-813

[8] Behrens SB, Deren ME, Matson A, Fadale PD, Monchik KO. Stress fractures of the pelvis and legs in athletes: a review. Sports Health 2013; 5: 165-174

[9] Belcher A. Ueber den Einfluss des Parademarches auf dieEntstehung der Fussgeschwulst. Med Klin 1905; 1: 305-306

[10] Bencardino JT, Palmer WE. Imaging of hip disorders in athletes. Radio Clin North Am 2002; 40: 267-287 vi-vii

[11] Berg EE. Femoral neck stress fracture. Orthop Nurs 1991; 10: 53-55

[12] Blickenstaff LD, Morris JM. Fatigue fracture of the femoral neck. J Bone Joint Surg Am 1966; 48: 1031-1047

[13] Breugem S], Hulscher JB, Steller P. Stress fracture of the femoral neck in a young female athlete. Eur J Trauma Emerg Surg 2009; 35: 192

[14] Carpintero P, Leon F, Zafra M, Serrano-Trenas JA, Roman M. Stress fractures of the femoral neck and coxa vara. Arch Orthop Trauma Surg 2003; 123: 273-277

[15] Cichy B, Roche SJ, Wozniak A. Atypical femoral neck stress fracture in a marathon runner: a case report and literature review. Ir J Med Sci 2012; 181: 427-429

[16] Clough TM. Femoral neck stress fracture: the importance of clinical suspicion and early review. Br J Sports Med 2002; 36: 308-309

[17] Devas MB. Stress fractures of the femoral neck. J Bone Joint Surg Br 1965; 47: 728-738

[18] Diwanji SR, Kong IK, Cho SG, Seon JK, Yoon TR. Displaced stress fracture of the femoral neck treated by valgus subtrochanteric osteotomy: 2 case studies. Am J Sports Med 2007; 35: 1567-1570

[19] Egol KA, Koval KJ, Kummer F, Frankel VH. Stress fractures of the femoral neck. Clin Orthop Relat Res 1998; doi:http://www.ncbi.nlm. nih.gov/pubmed/9553536 72-78

[20] Ejnisman L, Wajnsztejn A, Queiroz RD, Ejnisman B. Unusual presentation of a femoral stress fracture. BMJ Case Rep 2013, doi:10.1136/ bcr-2012-007828

[21] Enocson A, Lapidus L]. The vertical hip fracture - a treatment challenge. A cohort study with an up to 9 year follow-up of 137 consecutive hips treated with sliding hip screw and antirotation screw. BMC Musculoskelet Disord 2012; 13: 171

[22] Ernst J. Stress fracture of the neck of the femur. J Trauma 1964; 4 : 71-83

[23] Evans JT, Guyver PM, Kassam AM, Hubble M]. Displaced femoral neck stress fractures in Royal Marine recruits - management and results of operative treatment. J R Nav Med Serv 2012; 98: 3-5

[24] Fullerton LR Jr., Snowdy HA. Femoral neck stress fractures. Am J Sports Med 1988; 16: 365-377

[25] Goldin M, Anderson CN, Fredericson M, Safran MR, Stevens KJ. Femoral neck atress fractures and imaging features of femoroacetabular impingement. PM R 2015; 7: 584-592

[26] Goolsby MA, Barrack MT, Nattiv A. A displaced femoral neck stress fracture in an amenorrheic adolescent female runner. Sports Health 2012; 4: 352-356

[27] Haddad FS, Bann S, Hill RA, Jones DH. Displaced stress fracture of the femoral neck in an active amenorrhoeic adolescent. $\mathrm{Br}$ J Sports Med 1997; 31: 70-72
[28] Hajek MR, Noble HB. Stress fractures of the femoral neck in joggers: case reports and review of the literature. Am J Sports Med 1982; 10: $112-116$

[29] Hulkko A, Orava S. Stress fractures in athletes. Int J Sports Med 1987; 8: $221-226$

[30] Johansson C, Ekenman I, Tornkvist H, Eriksson E. Stress fractures of the femoral neck in athletes. The consequence of a delay in diagnosis. Am J Sports Med 1990; 18: 524-528

[31] Kaeding CC, Yu JR, Wright R, Amendola A, Spindler KP. Management and return to play of stress fractures. Clin J Sport Med 2005; 15: 442-447

[32] Kerr PS, Johnson DP. Displaced femoral neck stress fracture in a marathon runner. Injury 1995; 26: 491-493

[33] Krause DA, Newcomer KL. Femoral neck stress fracture in a male runner. J Orthop Sports Phys Ther 2008; 38: 517

[34] Kuhn KM, Riccio Al, Saldua NS, Cassidy J. Acetabular retroversion in military recruits with femoral neck stress fractures. Clin Orthop Relat Res 2010; 468: 846-851

[35] Kupferer KR, Bush DM, Cornell JE, Lawrence VA, Alexander JL, Ramos RG, Curtis D. Femoral neck stress fracture in Air Force basic trainees. Mil Med 2014; 179: 56-61

[36] Kupke M], Kahler DM, Lorenzoni MH, Edlich RF. Stress fracture of the femoral neck in a long distance runner: biomechanical aspects. J Emerg Med 1993; 11: 587-591

[37] Lee CH, Huang GS, Chao KH, Jean JL, Wu SS. Surgical treatment of displaced stress fractures of the femoral neck in military recruits: a report of 42 cases. Arch Orthop Trauma Surg 2003; 123: 527-533

[38] Lombardo SJ, Benson DW. Stress fractures of the femur in runners. Am J Sports Med 1982; 10: 219-227

[39] Neubauer T, Brand J, Lidder S, Krawany M. Stress fractures of the femoral neck in runners: a review. Res Sports Med 2016; doi:10.1080/ 15438627.2016.1191489 1-15

[40] Niva MH, Kiuru M], Haataja R, Pihlajamaki HK. Fatigue injuries of the femur. J Bone Joint Surg Br 2005; 87: 1385-1390

[41] O'Brien J, Taunton J, Larsen J, Forster BB. 31-year-old female runner with 5-week history of hip pain. Br J Sports Med 2011; 45: 136-139

[42] O’Kane JW. Anterior hip pain. Am Fam Physician 1999; 60: 1687-1696

[43] Okamoto S, Arai Y, Hara K, Tsuzihara T, Kubo T. A displaced stress fracture of the femoral neck in an adolescent female distance runner with female athlete triad: a case report. Sports Med Arthrosc Rehabil Ther Technol 2010; 2: 6

[44] Pihlajamaki HK, Ruohola JP, Kiuru M], Visuri TI. Displaced femoral neck fatigue fractures in military recruits. J Bone Joint Surg Am 2006; 88: 1989-1997

[45] Pihlajamaki HK, Ruohola JP, Weckstrom M, Kiuru MJ, Visuri TI. Long-term outcome of undisplaced fatigue fractures of the femoral neck in young male adults. J Bone Joint Surg Br 2006; 88: 1574-1579

[46] Polacek M, Smabrekke A. Displaced stress fracture of the femoral neck in young active adults. BMJ Case Rep 2010; 2010:

[47] Pouilles JM, Bernard J, Tremollieres F, Louvet JP, Ribot C. Femoral bone density in young male adults with stress fractures. Bone 1989; 10 : 105-108

[48] Provencher MT, Baldwin AJ, Gorman JD, Gould MT, Shin AY. Atypical tensile-sided femoral neck stress fractures: the value of magnetic resonance imaging. Am J Sports Med 2004; 32: 1528-1534

[49] Ramey LN, Mclnnis KC, Palmer WE. Femoral neck stress fracture: can MRI grade help predict return-to-running time? Am J Sports Med 2016, doi:10.1177/0363546516648319

[50] Rockwood CA GD Jr, Bucholz RW, Heckman JD. eds. Rockwood and Green's Fractures in Adults. Philadelphia: Lippincott-Raven; 1996 
[51] Scott MP, Finnoff JT, Davis BA. Femoral neck stress fracture presenting as gluteal pain in a marathon runner: case report. Arch Phys Med Rehabil 1999; 80: 236-238

[52] Scott S], Feltwell DN, Knapik J], Barkley CB, Hauret KG, Bullock SH, Evans RK. A multiple intervention strategy for reducing femoral neck stress injuries and other serious overuse injuries in U.S. Army Basic Combat Training. Mil Med 2012; 177: 1081-1089

[53] Shin AY, Gillingham BL. Fatigue fractures of the femoral neck in athletes. J Am Acad Orthop Surg 1997; 5: 293-302

[54] Shin AY, Morin WD, Gorman JD, Jones SB, Lapinsky AS. The superiority of magnetic resonance imaging in differentiating the cause of hip pain in endurance athletes. Am J Sports Med 1996; 24: 168-176

[55] Skinner HB, Cook SD. Fatigue failure stress of the femoral neck. A case report. Am J Sports Med 1982; 10: 245-247

[56] Spitz DJ, Newberg AH. Imaging of stress fractures in the athlete. Radiol Clin North Am 2002; 40: 313-331

[57] St Pierre P, Staheli LT, Smith JB, Green NE. Femoral neck stress fractures in children and adolescents. J Pediatr Orthop 1995; 15: $470-473$
[58] Sterling JC, Webb RF Jr., Meyers MC, Calvo RD. False negative bone scan in a female runner. Med Sci Sports Exerc 1993; 25: 179-185

[59] Taylor-Haas JA, Paterno MV, Shaffer MD. Femoral neck stress fracture and femoroacetabular impingement. J Orthop Sports Phys Ther 2011; 41: 905

[60] Visuri T, Vara A, Meurman KO. Displaced stress fractures of the femoral neck in young male adults: a report of twelve operative cases. J Trauma 1988; 28: 1562-1569

[61] Voss L, DaSilva M, Trafton PG. Bilateral femoral neck stress fractures in an amenorrheic athlete. Am J Orthop (Belle Mead NJ) 1997; 26: 789-792

[62] Wen DY, Propeck T, Singh A. Femoral neck stress injury with negative bone scan. J Am Board Fam Pract 2003; 16: 170-174

[63] Zacharias CK, Marsh HO. Jogging! a non-traumatic exercise? J Kans Med Soc 1980; 81: 563-565 